\section{CULTURA CORPORAL E EXPRESIONES MOTRICES: SOBRE A EDUCAÇÃO FÍSICA NO BRASIL E NA COLÔMBIA}

\author{
BODY CULTURE AND MOVEMENT EXPRESSIONS: ON PHYSICAL EDUCATION \\ IN BRAZIL AND COLOMBIA
}
CULTURA CORPORAL Y EXPRESIONES MOTRICES: SOBRE LA EDUCACION FÍSICA EN BRASIL Y COLOMBIA

Karen Lorena Gil Eusse*, Felipe Quintão Almeida*, Valter Bracht*
Palavras chave:

Educação Física.

Cultura.

Corpo humano.

Movimento.

Keywords:

Physical Education.

Culture.

Human body.

Movement.

Palabras clave: Educación Física.

Cultura.

Cuerpo humano.

Movimiento.
Resumo: Este artigo apresenta possíveis relações e comparações entre os movimentos de crítica e renovação da Educação Física no Brasil e na Colômbia, a partir do tratamento de duas perspectivas impactantes em ambos os países: Cultura Corporal e Expresiones Motrices. Depois de descrever algumas das características desses conceitos, finaliza com uma análise sobre seus pontos de (des)encontro.

Abstract: This paper presents possible relations and comparisons between the movements of criticism and renewal of Physical Education in Brazil and Colombia based on the treatment of two impactful approaches in both countries: Cultura Corporal (Body Culture) and Expresiones Motrices (Movement Expressions). After describing some characteristics of both concepts, the study analyzes their points of convergence/divergence.

Resumen: Este artículo presenta posibles relaciones y comparaciones entre los movimientos de crítica y renovación de la Educación Física en Brasil y Colombia, a partir del análisis de dos perspectivas influyentes en ambos países: Cultura Corporal y Expresiones Motrices. Después de describir algunas de las características de esos conceptos, finaliza con un análisis sobre sus puntos de (des)encuentro.
*Universidade Federal do Espírito Santo. Vitória, ES, Brasil. E-mail: kalogil@yahoo.es; fqalmeida@ hotmail.com; valter.bracht@pesquisador.cnpq.br

Recebido em: 29-11-2016 Aprovado em: 07-04-2017

\section{(c) (i) (9) Licence}




\section{INTRODUÇÃO}

Este texto analisa a proposta das Expresiones Motrices como desenvolvida na Colômbia, em uma espécie de diálogo comparativo com a proposição da Cultura Corporal presente no contexto brasileiro. A intenção de promover a discussão entre essas duas vertentes dá-se, principalmente, devido às (des)afinidades que apresentam e que podem ajudar a entender os percursos da Educação Física nos dois países, com os olhos de uma relação latino-americana. 0 texto começa contextualizando ambos os conceitos, para, no final, discutir algumas aproximações e distanciamentos.

\section{SOBRE A CULTURA CORPORAL}

A partir de meados do século $X X$, recrudesceu uma discussão em torno de um redimensionamento das práticas no campo acadêmico da Educação Física no Brasil. Nos anos 1970, por exemplo, ocorreu um movimento importante. Até então, o discurso e a teorização no campo tinham um caráter marcadamente pedagógico (BRACHT, 1999); a partir dessa época, essa inclinação perde força e se dá uma espécie de "despedagogização do teorizar em Educação Física" devido à necessidade de o campo se envolver num processo de cientifização, o que possibilitaria sua legitimação e "permanência no tempo" (BRACHT, 1999; PAIVA, 2003). Data dessa época, segundo Bracht (1999), uma série de medidas com influências diversas na organização da área: envio de professores para cursar pós-graduação no exterior, especialmente nos Estados Unidos da América; convênios e intercâmbios de pesquisa no exterior, por exemplo, na Alemanha; criação dos primeiros cursos de pósgraduação; implantação dos primeiros laboratórios de pesquisa com foco, sobretudo, na Fisiologia e Cineantropometria etc. Doravante, as práticas científicas passam a fazer parte, mais intensamente, da atividade acadêmica dos docentes do campo.

Este movimento de cientifização possibilitou, ao mesmo tempo, que a produção acadêmica da Educação Física se concentrasse, principalmente, no esporte, já que era este que dava a importância social, política e a legitimidade que tanto inquietava naquela altura. Nesse contexto, o fomento à pesquisa tinha como objetivo principal garantir a eficiência do sistema esportivo (e da Educação Física entendida, prioritariamente, como esporte). Esse novo olhar da Educação Física agora se preocupava com a maior eficiência no ensino das destrezas esportivas e não contemplava mais, como prioridade, a dimensão pedagógica do seu discurso e prática. Situação que se viu projetada na formação de professores de Educação Física, cujo currículo assumiu um caráter chamado por Betti e Betti (1996) de tradicional-esportivo. Esse processo de esportivização da Educação Física, que marcou a década de 1970 no Brasil e "[...] abriu a possibilidade de emergência de certa 'cultura esportiva', estendeu-se com intensidade até a década seguinte (particularmente, em seus primeiros anos), sendo possível a observância de suas implicações ainda nos dias atuais" (MACHADO, 2012, p. 57).

No final da década de 1970 e início de 1980, novas mudanças importantes ocorrem na área. Um movimento de intelectuais (retrospectivamente chamado Movimento Renovador da Educação Física - MREF), numa aproximação com as teorias críticas da Educação e da Sociologia do Esporte, faz uma crítica ao paradigma da aptidão física e desportiva que vinha sendo a marca registrada da área naqueles anos. Em outras palavras, operou uma crítica àquele processo de despedagogização em curso desde pelo menos os anos 1970, o que permitiu 
a reincorporação (mas, principalmente, a "ressignificação") das discussões pedagógicas em Educação Física, agora sob influência das chamadas Ciências Humanas. ${ }^{1}$ Assim, "[...] 0 MREF, ao se apropriar das teorias críticas da Educação e do Esporte, teria promovido/buscado uma espécie de 'virada' teórico-epistemológica/político-ideológica, principalmente na/para a Educação Física escolar" (MACHADO, 2012, p. 72).

Se, nos anos 1980, essa crise de identidade da Educação Física tinha um forte caráter político-ideológico, marcado por questionamentos sobre a função social que a disciplina (e os esportes) estava a cumprir na sociedade brasileira em tempos de redemocratização (pósditadura militar), na década seguinte ela assume uma dimensão mais epistemológica (LIMA, 1999), o que possibilitou discutir temas como seu objeto de estudo, seu estatuto epistemológico (a Educação Física é ou não ciência?), as matrizes teóricas predominantes no campo, entre outros. Nesse contexto, conforme Bracht (2013, p. 25), aparece com mais destaque a crítica à racionalidade técnico-científica e "Ganha força a necessidade de discutir 'qual cientificidade' reivindicar para a EF e mesmo, se ainda faz sentido reivindicar 'cientificidade' para a EF".

A partir desse panorama, surgem algumas tentativas para definir o objeto da Educação Física e propor alternativas ao paradigma da aptidão física e desportiva, que orientava, àquela altura, a Educação Física. Assim, aparecem perspectivas como o "Movimento Humano", "Movimento Corporal Humano", "Motricidade Humana", "Movimento Humano Consciente", "Cultura Corporal", "Cultura de Movimento" e "Cultura Corporal de Movimento" (BRACHT, 1999).

Merecem destaque, nesse contexto de disputa em torno do objeto da disciplina, duas perspectivas. A primeira delas, que não será analisada aqui, é a defendida pelo filósofo português Manuel Sérgio, cuja Ciência da Motricidade Humana se apresentou com uma alternativa bastante atraente ao paradigma da aptidão física e desportiva que sustentava, nos anos 1970-1980, as Ciências do Esporte no território brasileiro. ${ }^{2} \mathrm{O}$ impacto de suas teses no Brasil foi tal que influenciou renomados intelectuais e instituições do campo. ${ }^{3} \mathrm{~A}$ outra delas é representada pelo conceito de Cultura Corporal.

Essa maneira de definir o objeto de estudo da Educação Física, que é a que nos interessa neste artigo, corresponde à representação da dimensão histórico-social ou cultural do corpo e do movimento, proposta que tenta romper com a visão biologicista-mecanicista até então dominante na área. Segundo Souza Júnior (2011, p. 395), o conceito começa a ser utilizado em meados dos anos 1980,

[...] a partir das críticas realizadas por Dieckert (1985) à visão de esporte de alto nível [...]. $O$ autor buscava uma Educação Física mais humana dentro da concepção do 'Esporte para Todos', onde fosse discutida e criada uma 'nova antropologia' que colocasse como centro da questão 'uma cultura corporal própria do povo brasileiro'. Essa cultura própria do nosso povo foi definida pelo autor como: elaborações que as pessoas realizam em torno de suas próprias práticas corporais, construídas e reconstruídas em seu país - capoeira, jogos de diferentes regiões, danças brasileiras - elementos da 'cultura corporal que vive no Brasil e no povo brasileiro'.

O que vai se tornar fundamental, nesse contexto, é o imperativo de tomar a cultura como dimensão norteadora da Educação Física (BRACHT, 2014). Nas palavras de Pich (2014, p. 164-165),

\footnotetext{
1 Em especial, conforme demonstram Bracht et al. (2012) e Della Fonte (2001), influenciado pela perspectiva marxista.

2 Uma análise dessa perspectiva pode ser encontrada em Bracht (1999).

3 Em especial, o Colégio Brasileiro de Ciências do Esporte (CBCE) e a Unicamp, que pretendeu refundar sua Faculdade de Educação Física como instituto de Ciência da Motricidade Humana.
} 
Podemos dizer que até o presente momento a tentativa de referenciar a Educação Física na cultura permitiu grandes avanços na área no sentido de superar uma perspectiva reducionista de concepção de ser humano. [...] Assim sendo, a superação da visão biologicista-mecanicista do corpo e do movimento possibilitou abandonar a crença na possibilidade de orientar uma prática corporal meramente por princípios técnicos ou tecnocientíficos, desvinculada de toda e qualquer orientação pedagógico-política. Finalmente apontamos o retorno ao símbolo no corpo e do corpo.

O conceito da Cultura Corporal ${ }^{4}$ aparece de modo sistematizado, pela primeira vez, na obra Metodologia de ensino da educação física, mais conhecida como "Coletivo de autores". O livro foi publicado em 1992 e assinado por seis autores. Assume o materialismo históricodialético como teoria fundamental das reflexões ali contidas e apresenta à comunidade uma pedagogia emergente, chamada de crítico-superadora, que busca responder a determinados interesses de classe. Nessa perspectiva, a reflexão pedagógica é "diagnóstica, judicativa e teleológica":

Diagnóstica, porque remete à constatação e leitura dos dados da realidade. Esses dados carecem de interpretação, ou seja, de um julgamento sobre eles. Para interpretá-los, o sujeito pensante emite um juízo de valor que depende da perspectiva de classe de quem julga, porque os valores, nos contornos de uma sociedade capitalista, são de classe. Dessas considerações resulta que a reflexão pedagógica é judicativa, porque julga a partir de uma ética que representa os interesses de determinada classe social. É também teleológica, porque determina um alvo onde se quer chegar, busca uma direção. Essa direção, dependendo da perspectiva de classe de quem reflete, poderá ser conservadora ou transformadora dos dados da realidade diagnosticados e julgados (CASTELLANI FILHO et al., 2009, p. 27).

No âmbito dessa perspectiva, a Educação Física Escolar é uma prática pedagógica que matiza formas de atividades expressivas corporais, como jogo, esporte, dança, ginástica etc. $O$ estudo desse conhecimento pretende, conforme aprendemos no livro (CASTELLANI FILHO et al., 2009), assumir a expressão corporal como linguagem, de maneira que:

0 homem se apropria da cultura corporal dispondo sua intencionalidade para 0 lúdico, o artístico, o agonístico, o estético ou outros, que são representações, idéias, conceitos produzidos pela consciência social e que chamaremos de 'significações objetivas'. Em face delas, ele desenvolve um 'sentido pessoal' que exprime sua subjetividade e relaciona as significações objetivas com a realidade da sua própria vida, do seu mundo e das suas motivações (CASTELLANI FILHO et al., 2009, p. 62).

De lá para cá, embora possamos identificar críticas ao livro e ao materialismo históricodialético (CAPARROZ, 1997; OLIVEIRA, 2001), esse conceito alcançou certo consenso no âmbito das chamadas perspectivas críticas de Educação Física. ${ }^{5}$ Uma expressão disso é que ele é encontrado em bibliografias dos concursos públicos, nos referenciais curriculares existentes no Brasil, nas formações iniciais e continuadas, nas dissertações, teses, revistas da

4 Conforme demonstram Souza Júnior et al. (2011), há, entre os próprios signatários do "Coletivo de autores", discordâncias quanto ao uso das expressões Cultura Corporal ou Cultura Corporal de Movimento. Por exemplo, Celi Taffarel prefere a expressão Cultura Corporal; Valter Bracht, por sua vez, o conceito de Cultura Corporal de Movimento (SOUZA JÚNIOR et al., 2011). Em muitos casos, os termos são tomados como sinônimos.

5 Consenso não significa ausência de outras concepções em disputa com o próprio conceito de Cultura Corporal ou Cultura Corporal de Movimento. Esse é o caso da Cultura de Movimento (termo que aparece nos trabalhos de Elenor Kunz) e o que Oliveira (2014) denomina de 
área etc. É possível dizer, também, que seu uso não se vincula necessariamente ao "Coletivo de autores" e ao referencial teórico do livro, mas é assumido por autores que operam a partir de perspectivas conceituais bastante distintas. A despeito dessas diferenças, o conceito de Cultura Corporal é chave para se entender os recentes movimentos de renovação e crítica que a Educação Física brasileira experimentou nas últimas décadas.

A seguir, apresentaremos a compreensão de Expresiones Motrices para, na sequência, traçarmos paralelos entre esse conceito e a Educação Física pensada a partir da perspectiva da Cultura Corporal.

\section{SOBRE AS EXPRESIONES MOTRICES}

De forma análoga ao que se passou no Brasil, a Colômbia também apresentou momentos de crítica e renovação da tradição da Educação Física. Urrego (2007) compreende essa tradição, na Colômbia, como físico-desportiva, fundamentada numa racionalidade técnicoinstrumental. Em grande medida, seu estabelecimento está fortemente relacionado com a influência da Alemanha Ocidental no campo da Educação Física colombiana, nas décadas de 1970 e 1980, especialmente devido às assessorias que autores alemães realizaram no país (PINILLOS, 2011). Nesse contexto, a discussão sobre a cientificidade da disciplina foi marcada, segundo Pinillos (2011), pelo conceito de Ciencia del Deporte proveniente dos alemães, que reforçava o corte instrumental da disciplina e rompia com seu caráter pedagógico, já que o objetivo a ser privilegiado era o rendimento esportivo.

A crítica inicial a essa tradição tecnicista foi impulsionada por movimentos estudantis da Educação Física, provenientes de faculdades públicas do país. Cuba, por estar vinculada a lutas de revolução em relação ao sistema socioeconômico dominante, foi tomada como referência na busca por caminhos alternativos. Surge, assim, o vínculo com o conceito de Cultura Física proveniente de Cuba e que influenciou a produção acadêmica e mesmo a prática da Educação Física na Colômbia. A partir desse contato com os cubanos, alguns personagens do campo tomam conhecimento de uma literatura advinda da Alemanha Oriental, também acolhida, no início, pelo fato de estar relacionada com as lutas comunistas, ainda que, paradoxalmente, essa literatura da Alemanha comunista continuasse motivando a prática tecnicista de Educação Física que tanto queriam ver superada. ${ }^{6}$

Dentro dos diversos episódios no debate sobre a necessidade de uma mudança e, sobretudo, na procura pela "identidad disciplinar y professional" (PINILLOS, 2011), outra corrente aparece para deixar uma marca importante no país andino. Trata-se da psicomotricidade de origem francesa, que se posiciona como contraposição às teorias "[...] mecanicistas - biologistas, de la educación 'para' el movimiento que hasta ese momento direccionaban el hacer de la disciplina" (BENJUMEA, 2004, p. 6). Segundo Gallo (2007, 2010), a psicomotricidade de Jean Le Boulch ${ }^{7}$ foi um dos pensamentos mais influentes na constituição dos discursos contemporâneos da Educação Física colombiana. Descreve a respeito:

Desde la aproximación psicopedagógica en la que se inscribe Jean Le Boulch, más específicamente en la educación psicomotriz, surge el método de la psicokinética

\footnotetext{
6 Essa interpretação da crítica à tradição tecnicista da Educação Física vinculada aos movimentos estudantis na Colômbia foi tomada de entrevistas por nós realizadas com personagens que participaram daquela crítica nos anos 1980. Essa temática está sendo desenvolvida como parte de uma tese de doutorado e, por conta dos objetivos deste texto, não será aprofundada aqui.

7 A autora desenvolve a ideia dos quatro pensadores mais influentes na Educação Física colombiana atual: Jean Le Boulch, José María Cagigal, Pierre Parlebas e Manuel Sérgio (GALLO, 2007, 2010).
} 
que aparta a Le Boulch de los métodos tradicionales de la Educación Física y pretende ser una herramienta metodológica que utiliza el movimiento humano como un medio de educación para el desarrollo de la persona (GALLO, 2007, p. 50).

A presença de "outras vozes" no campo expressava-se nos artigos publicados nas revistas, em renovações curriculares, nas discussões em congressos e eventos acadêmicos, no diálogo com a literatura internacional etc. Põe-se em questão o caráter científico da área, ao mesmo tempo em que se discutem aspectos associados ao seu objeto de estudo, a despedagogização, as mudanças semânticas, o campo de atuação profissional, a formação profissional, a fundamentação epistemológica etc. Os movimentos de crítica e renovação propiciaram um debate no país que até hoje continua em movimento e que apresenta uma gama ampla de possibilidades de análise. Diz Urrego (2012, p. 141) que:

Estamos ante un fenómeno expansivo que es cada vez más contrario al ideal de una Educación física universal, con principios uniformes, con una única definición o con unos solos procedimientos de actuación. La diversidad y la interacción entre las temáticas manifestadas en el campo profesional conforman un estado de tensiones y de permanente complejidad del campo.

Essa Educação Física diversificada que menciona o autor vê-se projetada na variedade de propostas e conceitos para tratar do campo na atualidade. Com a pretensão de caracterizar a Educação Física como área do conhecimento distinta da Ciencia del Deporte, surgem, na Colômbia, outras terminologias. Além da Psicomotricidade e da Cultura Física, podemos citar a Motricidad, a Motricidad Humana, a Educación Corporal, a Actividad Física, a Experiencia Corporal, as Prácticas Corporales, ${ }^{8}$ as Expresiones Motrices, entre outras. Este texto, conforme anunciado, tratará desta última perspectiva.

O conceito de Expresiones Motrices foi alvitrado na Colômbia pela professora Rubiela Arboleda Gómez. ${ }^{9}$ Ela aponta que o conceito surge pela necessidade de nomear certas práticas que não correspondiam às práticas tradicionais da Educação Física e que se enfocavam ao campo escolar. Desse modo, com o passar do tempo, vem se preocupando por fundamentar o conceito devido, entre outras justificativas, à demanda do campo acadêmico a esse respeito. 0 movimento que ela fez, portanto, não foi o de estudar autores ou correntes para formular uma proposta, mas, sim, como ela mesma afirma (ARBOLEDA, 2013), criar o conceito para depois procurar fundamentação na literatura. ${ }^{10}$

Em entrevista concedida a uma colega, na Argentina, Arboleda (MOLEJÓN, 2011, p. 132) explica que o conceito surgiu a partir da necessidade de nomear um exercício realizado com mães em processo de gestação. Ela diz sobre o conceito:

Cuando lo propuse trabajaba con embarazadas, con gestantes, e iba a hacer mi tesis en antropología y quería hablar de eso, de las prácticas con gestantes como un rito de paso contemporáneo, pero no sabía cómo denominar las prácticas que se realizaban con estos grupos, no cabían en la noción de educación física, no cabían en la de deporte, ni cabían en la de recreación [...]. Así las cosas, no encontraba dónde ubicar estas prácticas con gestantes y, paralelamente, comenzaron a emerger un montón de prácticas en el contexto que no cabían... con

8 Algumas dessas perspectivas serão analisadas numa tese de doutorado, em andamento.

9 A professora Rubiela é doutora em Estudios Científicos Sociales do Instituto Tecnológico y de Estudios Superiores de Occidente (Iteso) Guadalajara, México; mestre em Problemas Sociales Contemporáneos e Antropóloga; e licenciada em Educação Física da Universidad de Antioquia (Medellín, Colômbia). Atualmente atua como docente e investigadora nesta última Universidade.

10 Nesse contexto, ela viu necessidade de "[...] encontrar arraigos conceptuales, esto es, tejidos terminológicos, vocablos, dicciones, avalados por la modernidad positiva, que respalden a proposta" (ARBOLEDA, 2013, p. 91). 
hipertensos, con obesos, con población de niños en situación de calle, entre otras. Entonces necesitamos una noción que fuera integradora, una suerte de 'campo semántico', que nos permita un piso referente y que a la vez posibilite abrirse a toda esa variedad de prácticas que tenemos, pensando en el sujeto, en que la motricidad implica dejar salir al sujeto y un poco 'descreída' de la idea de la acción.

Um primeiro aspecto a destacar dessa citação é a insuficiência da expressão Educação Física para dar conta da multiplicidade de práticas, cenários e indivíduos que põem o corpo em movimento. Em outras palavras, as Expresiones Motrices são um cenário de exibição de manifestações de ordem cultural que fogem dos conceitos tradicionais que vêm operando a área da Educação Física. Ainda sobre o conceito de Educação Física e sua relação com o das Expresiones Motrices, ela narra:

[...] el profesor Hendricks, a quien muchos seguíamos por su actitud crítica y en ocasiones anticipada, introdujo la sospecha sobre el denominador Educación Física; alguna vez dijo, parafraseándolo a la luz del recuerdo: 'esa noción también es cuestionable y es muy dualista', lo que significó una suerte de 'parte aguas' en mi reflexión; empecé a pensar que era necesario un término que correspondiera a lo que queríamos de este saber y surgió la necesidad de replantear también al sujeto del conocimiento (ARBOLEDA, 2013, p. 61).

Arboleda (2013) afirma que o termo Educação Física possui um problema semântico, pois a Educação teria o propósito de transformar o "instinto" pela aprendizagem, lugar em que o físico seria o objeto dessa transformação. Assim, a Educação Física conota uma estrutura dual que separa natureza e cultura e trata o corpo como o lugar do natural, que requer ser dominado, é orgânico - mecânico. Para ela, educar o físico não demarca o nosso saber-fazer. Desse modo, devido aos questionamentos desde o nominativo da Educação Física, propõe o conceito de Expresiones Motrices, que "Es un concepto incluyente, visibilizador; es una acepción integradora que, paradójicamente, admite la variedad de los actores, de prácticas y de representaciones" (ARBOLEDA, 2013, p. 69). A autora acrescenta que:

[...] la denominación expresiones motrices, [...] hace referencia a aquellas manifestaciones de motricidad que se realizan con distintos fines: lúdico, agonístico, estético, preventivo, de mantenimiento, de rehabilitación y de salud entre otros, organizadas siguiendo una lógica interna, que establece un código legitimado en un contexto social, y por el cual se admiten y/o prohíben unos gestos se ofrecen pautas de comportamiento, se crean actitudes y se promueven creencias (ARBOLEDA, 2004, p. 92).

Arboleda (2010) aponta algumas caraterísticas dos laços entre as Expresiones Motrices e a cultura. Por exemplo, a existência dos códigos éticos corporais que demarcam a vida em sociedade, a simbologia comunicacional que produz o corpo e o movimento, ${ }^{11}$ a etnomotricidad (símbolos corporais como identidade de cada comunidade), entre outras (ARBOLEDA, 2010). A relação das Expresiones Motrices com a cultura tem, ao mesmo tempo, implicações para a constituição de cidadania:

[...] las expresiones motrices son una metáfora de la cultura y de la vida social. La motricidad en general y las expresiones motrices en particular, históricamente han acompañado a la humanidad en la manifestación de sentidos como el ético, el estético, el agonista, el bienestar, la sanación, la formación, la lúdica, el gregarismo. Una panorámica a la historia da cuenta de la presencia de la motricidad en las grandes búsquedas colectivas y en las manifestaciones más íntimas del sujeto.

11 Os conceitos de corpo e motricidade representam o sentido fundamental das Expresiones Motrices (ARBOLEDA, 2013). 
Cada época y cada territorio ha enfatizado en uno u otro aspecto según sus propias lógicas, piénsese en el afán de procurarse alimentos de los primeros tiempos; en la fascinación por la guerra, una constante histórica; en la dedicación a la salud y la belleza en la polis griega; en la nostalgia de comunidad, característica del mundo contemporáneo. Y allí, en esas circunstancias connaturales a la vida humana, las expresiones motrices han operado como soporte y posibilidad (ARBOLEDA, 2010, p. 20).

Além da necessidade de ampliar o leque de possibilidades da motricidade e de destacar a dimensão cultural encarnada nas manifestações motrizes, o conceito de Expresiones Motrices se desenvolve a partir da preocupação em encontrar uma alternativa de prática às dominadas pela ciência moderna, ${ }^{12}$ perspectiva à qual a Educação Física se vinculou e em que tão bem se expressou na lógica do esporte moderno (ARBOLEDA, 2008). ${ }^{13}$ Nesse contexto, a proposta das Expresiones Motrices dá um especial tratamento ao tema do corpo que, em coerência com a crítica feita à aplicabilidade exclusiva da ciência moderna na Educação Física, trata o corpo como um espaço sociocultural que não se restringe à sua interpretação desde o biológico, que fragmenta, fratura, mede e objetiva. Segundo Arboleda (2004), a busca por um posicionamento científico levou a Educação Física a construir uma identidade "parasitária" das ciências básicas que, de acordo com a concepção moderna, é o lugar em que o corpo é tratado como objeto, passível de modificação e intervenção por meio da ciência. Segundo as palavras da própria autora (ARBOLEDA, 2004, p. 95),

El cuerpo, por mucho tiempo, ha sido fragmentado, fracturado, medido, objetivado por la modernidad positivista y, consecuentemente, las expresiones motrices, particularmente el deporte, han sido subsidiarias de esta concepción, y devienen en prácticas más automatizantes que liberadoras, una especie de racionalidad de la motricidad que oculta al sujeto. Aún hoy existen algunos vestigios que sitúan al área como sobreviviente de la modernidad positivista: los dualismos: el concepto de Educación Física, dualista per se, que encierra, por lo demás, la escisión naturaleza/cultura; dualismos consuetudinarios como cuerpo/espíritu, filogenia/ ontogenia, masculino/feminino, viejo/joven, técnica/expresión, racionalismo/ percepción; la consolidación de modelos diferenciadores, ya sea desde la salud, la pedagogía, la competencia, que limitan las prácticas y generan doctrinas y doctrinantes.

Outro ponto crucial para se entender o contexto de surgimento das Expresiones Motrices, e sem perder de vista o que foi discutido acima, tem a ver com a crítica que a autora fará ao esporte de rendimento como fator de representação da área. A proposta das Expresiones Motrices pretende ampliar as lógicas reducionistas do esporte. Mais explicitamente, a autora (ARBOLEDA, 2004) expõe que as Expresiones Motrices são uma "criação cultural" tocada pelas comunidades e contextos específicos em que se desenvolvem. Para ela, o esporte, especialmente em tempos de globalização, não tem esta caraterística de criação particular de cada cultura, mas, pelo contrário, opera com formas estandardizadas e unificadoras desde, por exemplo, as estratégias de treinamento, técnicas, códigos gestuais, desenho de cenários e mercantilização dos jogadores. Apesar desse panorama, a autora também reconhece que 0

12 Tentando se opor a essa realidade, a autora trabalha com o conceito de modernidade reflexiva para tratar o corpo como uma dimensão integral, como um constructo social que se conecta ao contexto e à cultura. Modernidade reflexiva é um conceito empregado pelos sociólogos Anthony Giddens, Ulrich Beck e Scott Lash para caracterizar a sociedade contemporânea. A autora (2008) explica que 0 conceito remete a uma ruptura estrutural das lógicas positivistas da ciência moderna. Trata-se de uma possibilidade de aproximação entre o senso comum e o conhecimento científico, entre sujeito e objeto e o reconhecimento dos limites da ciência moderna, o que permite formas mais amplas e diversas para compreender e se relacionar com o conhecimento e a vida. 
esporte tem representado uma significativa importância para a área, pois tem impulsionado a desejada cientifização que tem possibilitado a "redenção de identidades" para um grupo que acredita ser essa a especificidade da área. ${ }^{14}$

Ao pensar nas Expresiones Motrices no âmbito escolar, a autora (2013) usa a noção de "Florecimiento Humano"15 e apresenta (ARBOLEDA, 2004) alguns princípios didáticos que permitem, segundo ela, explorar o potencial formador das Expresiones Motrices. Eles são: a integralidade (corpo como uma unicidade), a corporeidade (consciência corporal), a motogênesis (potencial motriz de cada sujeito) e a contextualidade (sujeito marcado pelo entorno). Ao mesmo tempo, expõe estratégias didáticas para dialogar com ditos princípios a partir da etnomotricidad, interacción, historicidad, otredad e esteticidad que servem para avaliar o movimento corporal.

A ideia de Expresiones Motrices, rapidamente aqui apresentada, é de grande repercussão no contexto colombiano, principalmente no Departamento ${ }^{16}$ de Antioquia. Segundo Urrego (2014), tem sido implementada na política pública de educação para a área de Educação Física e tem aberto projetos e linhas de pesquisa no contexto nacional que discutem as dimensões que o termo projeta. Na formação e no currículo da Universidade de Antioquia também é fortemente evocada.

\section{OS (DES)ENCONTROS}

Encerramos com aspectos comuns a ambas as propostas. Para isso, começamos destacando que as necessidades de mudanças semânticas, tanto no Brasil como na Colômbia, parecem ter sido motivadas, entre outros aspectos, pela crítica ao esporte como linha central na prática da Educação Física. No caso brasileiro, a Cultura Corporal se apresentou como uma alternativa ao paradigma da aptidão física e/ou desportiva. Na Colômbia, a adoção das Expresiones Motrices visou a ampliar o espectro semântico da atuação na disciplina, não restrita apenas às práticas esportivas e às escolares. Contudo, e diferentemente do que se passa com a Cultura Corporal, entendida como objeto de estudo ou área do conhecimento de que trata a Educação Física (e, por isso, vê a escola como o lócus por excelência de desenvolvimento de sua proposta), a perspectiva de Arboleda vai além e propõe a substituição do termo Educação Física por Expresiones Motrices, entendendo a escola como apenas um dos cenários possíveis de sua manifestação.

Além disso, as tentativas brasileira e colombiana de mudar a terminologia partiram da necessidade de vincular outro tipo de prática, menos enraizada nas lógicas reducionistas da ciência moderna. Elas representam, assim, um questionamento da cientifização da disciplina na esteira de uma determinada compreensão da ciência, frouxamente chamada da positivista. Advogam, assim, que a Educação Física e as Expresiones Motrices devem ter outra relação com as ciências (mãe), caracterizadas por uma autonomia relativa orientada a partir das necessidades da própria intervenção.

\footnotetext{
14 É possível dizer que, na Colômbia, ainda hoje predomina um pensamento mais tradicional (esportivo) a respeito da Educação Física. Isso é visível quando observamos os "campos de interesse da área" veiculados na produção de conhecimento. Nos periódicos estudados por Urrego (2014), aparecem as seguintes porcentagens por categorias: Deporte, rendimiento y competición (45\%), Actividad física para prevención de la enfermedad y promoción de salud (10\%), Pedagogía, educación y escuela (31\%); Ocio, recreación, lúdica y juego (7\%) e Otras temáticas registradas (8\%). Assim como no Brasil, há predomínio das pesquisas vinculadas à chamada área biodinâmica (CARVALHO; MANOEL, 2011). 15 Expressão que remete à ideia de formação na "florescência" do sujeito, "[...] que no es otra cosa que satisfacer las necesidades de acuerdo con las capacidades individuales; potencializarse en un contexto que lo estimule y admita" (ARBOLEDA, 2013, p. 220). 
Essa crítica à cientifização da Educação Física, no caso de ambas as propostas, levou a um questionamento da compreensão de corpo e de movimento, numa tentativa de romper com a visão biologicista-mecanicista até então dominante na área (nos dois países). Como consequência, elas resultam na defesa do caráter cultural do corpo, no incremento de um discurso sobre a Cultura Corporal ou, então, sobre as Expresiones Motrices que fazem parte do contexto colombiano. Isso levou, tanto no caso brasileiro como no caso colombiano, a uma reaproximação da Educação Física com o discurso das Ciências Humanas e Sociais. Nessas circunstâncias, todas as manifestações corporais são produzidas na dinâmica cultural humana, "[...] desde os primórdios da evolução até hoje, expressando-se diversificadamente e com significados próprios no contexto de grupos culturais específicos" (DAOLIO, 2014, p. 162). ${ }^{17}$

A despeito dessas afinidades, é importante destacar que o referencial teórico que fundamentou as reflexões das perspectivas em tela é bastante distinto. No caso brasileiro, 0 primeiro tratamento mais sistematizado da Cultura Corporal foi feito a partir do materialismo histórico-dialético. Esse não é o caso das Expresiones Motrices, cujo referencial não parece ter uma única linha e, portanto, uma corrente teórica que a fundamente. ${ }^{18}$ Arboleda (2008) menciona o conceito de "modernidade reflexiva" como uma referência importante para sua proposta. Cita os autores Boaventura de Souza Santos e Jaime Breilh para "[...] consolidar la disertación epistemológica que ofrezca um piso a la noción [...]" (ARBOLEDA, 2013, p. 46) e autores como Cassirer, Nicole, Colli, Jacson e Spinoza para justificar o conceito proposto. 0 uso desse termo indica um pertencimento teórico muito distinto daquele que deu origem ao uso de Cultura Corporal, embora, como dissemos, esse termo não esteja mais vinculado apenas à tradição do marxismo, uma perspectiva cuja trajetória no campo da Educação Física brasileira é conhecida.

É importante aclarar que ambos os "paradigmas", como dissemos, tiveram grande impacto em seus países. Vários referenciais curriculares no Brasil, como outros documentos e currículos de cursos na Colômbia, são influenciados pelas propostas em tela. Sem embargo, não são hegemônicos em nenhum dos dois contextos.

Cabe destacar que esses pontos de (des)encontro proporcionados por esse tipo de diálogo podem ajudar a pensar os processos que têm resultado em uma renovação ou na construção de um pensamento crítico da Educação Física na América Latina. Trata-se de um exercício importante, pois, como apontam Silva et al. (2015), as realidades regionais da Educação Física latino-americana são pouco conhecidas entre seus pares, e a produção acadêmica a respeito dos contextos e da interlocução entre elas é muito escassa, por isso a importância da pesquisa (comparada) que possibilite a aproximação entre essas nações irmãs, com fim de, entre outras questões, superar as influências externas às necessidades próprias de uma cultura latino-americana.

\section{REFERÊNCIAS}

ARBOLEDA, Rubiela Gómez. Las expresiones motrices en América Latina en la tensión global - local: una apuesta desde la corporeidad, en el marco de la modernidad reflexiva. Apunts Educación Física y Deportes, v.4, n. 78, p. 91-97, 2004.

17 Não surpreende a crítica de Arboleda (2004) ao caráter estandardizante e/ou globalizante do esporte moderno, exatamente por ele desconsiderar as dinâmicas próprias a cada cultura. 
ARBOLEDA, Rubiela Gómez. Las expresiones motrices, una representación:

Hacia la configuración del campo académico. EF Deportes, n. 119, 2008. Disponível em: < http:// www.efdeportes.com/efd119/las-expresiones-motrices.htm>. Acesso em: 20 out. 2016.

ARBOLEDA, Rubiela Gómez. Las expresiones motrices y la construcción de ciudadanía: una reflexión desde las experiencias significativas. Educación Física y Ciencia, v.12, p. 13-23, 2010.

ARBOLEDA, Rubiela Gómez. Las expresiones motrices. Armenia (Colombia): Kinesis, 2013.

BENJUMEA, Margarita María. La motricidad, corporeidad y pedagogía del movimiento en educación física: un asunto que invita a la transdisciplinariedad. In: CONGRESO CIENTÍFICO LATINO-AMERICANO. 3.; SIMPÓSIO LATINO-AMERICANO DE MOTRICIDAD HUMANA. 1., 2004. Disponível em: <http://viref.udea.edu.co/contenido/pdf/04 la motricidad corporeidad.pdf>. Acesso em: 20 out. 2016.

BETTI, Irene Rangel.; BETTI, Mauro. Novas perspectivas na formação profissional em educação física. Motriz, v. 2, n. 1, p. 10-15, jun. 1996.

BRACHT, Valter. Educação física e ciência: cenas de um casamento (in)feliz. 2. ed. ljuí: Unijuí, 1999.

BRACHT, Valter. Epistemologia, ensino e crítica: desafios contemporâneos. In: GOMES, I. M.; ALMEIDA, F. Q.; VELOZO, E. Epistemologia, ensino e crítica: desafios contemporâneos para a educação física. Nova Petrópolis: Nova Harmonia, 2013. p. 19-30.

BRACHT, Valter. Traçados analíticos e esforços de autointerpretação: uma entrevista com Valter Bracht. In: ALMEIDA, F. Q.; GOMES, I. M. (Org.). Valter Bracht e a educação física: um pensamento em movimento. ljuí: Unijuí, 2014. p. 237-313.

BRACHT, Valter et al. A Educação Física Escolar como tema da produção do conhecimento nos periódicos da área no Brasil (1980-2010): parte II. Movimento, v. 18, n. 2, p. 11-37, abr./jun. 2012.

CAPARROZ, Francisco Eduardo. Entre a educação física na escola e a educação física da escola. Vitória: UFES, 1997.

CARVALHO, Yara; MANOEL, Edson de Jesus. A pós-graduação em educação física brasileira: a atração (fatal) para a biodinâmica. Educação e Pesquisa, v. 37, n. 2, p. 389-406, maio/ago. 2011.

CASTELLANI Filho, Lino et al. Metodologia do ensino de educação física. São Paulo: Cortez, 2009.

DAOLIO, Jocimar. Cultura. In: GONZÁLEZ, F.; FENSTERSEIFER, P. E. (Org.). Dicionário crítico de educação física. ljuí: Editora Unijuí, 2014. p. 161-163.

DELLA FONTE, Sandra Soares. O passado em agonia: da criação de reducionismos ou sobre como matar a historicidade. In: CAPARRÓZ, F. E. Educação física escolar. Vitória: Proteoria, 2001. p. 169192.

GALLO, Luz Elena. Cuatro hermenéuticas de la educación física en Colombia. In: CHAVERRA, Beatriz Elena, URIBE; Iván Dário (Org.). Aproximaciones epistemológicas y pedagógicas a la educación física: un campo en construcción. Medellín: Funámbulos Editores, 2007. p. 45-94.

GALLO, Luz Elena. Los discursos de la educación física contemporánea. Bogotá: Kinesis, 2010.

LIMA, Homero Luis de Alves. Pensamento epistemológico da educação física brasileira: uma análise crítica. In: FERREIRA NETO, A. (Org.). Pesquisa histórica na educação física. Aracruz: Facha, 1999. v. 4, p. 117-138. 
MACHADO, Thiago da Silva. Sobre o impacto do movimento renovador da educação física nas identidades docentes. 2012. 191f. Dissertação (Mestrado em Educação Física) - Programa de PósGraduação em Educação Física da Universidade Federal do Espírito-Santo, Vitória, 2012.

MOLEJÓN, Amanda. Sobre cuerpo y... ¿Educación Física? ¿Educación Corporal? ¿Expresiones Motrices? Entrevistada Rubiela Arboleda Gómez. Educación Física y Ciencia, n. 13, p. 129-137, 2011.

OLIVEIRA, Marcus Aurélio Taborda. Para uma crítica da historiografia: as relações entre a ditadura militar e a educação física brasileira e a negação da experiência escolar do professor de educação física. In: FERREIRA NETO, A. (Org.). Pesquisa histórica na educação física. Vitória: Proteoria, 2001. v. 6, p. 5-48.

OLIVEIRA, Marcus Aurélio Taborda. Corporalidade. In: GONZÁLEZ, F.; FENSTERSEIFER, P. E. (Org.). Dicionário crítico de educação física. ljuí: Editora Unijuí, 2014. p. 153-157.

PAIVA, Fernanda Simone Lopes de Paiva. A constituição do campo da educação física no Brasil: ponderações acerca de sua especificidade e autonomia. In: BRACHT, V. CRISÓRIO, R. Educação física no Brasil e na Argentina: identidade, desafios e perspectivas. Campinas: Autores Associados, Rio de Janeiro: Prosul, 2003. p. 63-80.

PICH, Santiago. Cultura corporal de movimento. In: GONZÁLEZ, F.; FENSTERSEIFER, Paulo Evaldo (Org.). Dicionário crítico de educação física. ljuí: Editora Unijuí, 2014. p. 108-111.

PINILLOS, Jesús María. La constitución del campo de la educación física en Colombia en el periodo comprendido entre 1968 y 1991. Recorde: Revista de História do Esporte, v. 4, n. 2, p. 1-23, dez. 2011.

SILVA, Ana Márcia et al. Caracterização da formação profissional no campo da educação física na América Latina. In: SILVA, A. M.; BEDOYA, V. M. (Org.). Formação profissional em educação física na América Latina: encontros, diversidades e desafios. Jundiaí: Paco Editorial, 2015. p. 279-312.

SOUZA JÚNIOR, Marcílio et al. Coletivo de autores: a cultura corporal em questão. Revista Brasileira de Ciências do Esporte, v. 33, n. 2, p. 391-411, abr./jun. 2011.

URREGO, Léon Jaime. Educación física escolar: el sentido formativo de un área que no cuestiona la tradición. In: CHAVERRA, B. E. F.; URIBE, I. D. P. (Org.). Aproximaciones epistemológicas y pedagógicas a la educación física: un campo en construcción. Medellín: Funámbulos, 2007. p. 207225.

URREGO, Léon Jaime. Un análisis parcial a la producción académica en el campo profesional de la educación física en Colombia. Revista Brasileira de Ciências do Esporte, v. 34, n. 1, p.127-148, jan./mar. 2012.

URREGO, Léon Jaime. Estudio de la producción de conocimiento en la educación física en Colombia entre 1990 y 2006. 2014. 510f. Tese (Doctorado en Didáctica de la educación artística: educación física) - Universidad de Valladolid, 2014. 